\title{
Mitochondrial myopathy and lactic acidaemia with myoclonic epilepsy, ataxia and hypothalamic infertility: a variant of Ramsay-Hunt syndrome?
}

\author{
ROBIN B FITZSIMONS, P CLIFTON-BLIGH, AND W H WOLFENDEN \\ From The Departments of Neurology and Endocrinology, Sydney Hospital, and The Department of Medicine, \\ University of Sydney, Sydney, Australia
}

S UMMARY A case of mitochondrial myopathy and lactic acidaemia with myoclonic epilepsy, cerebellar ataxia and high-tone hearing loss is presented. There was no ptosis or ophthalmoplegia. Endocrine investigations showed a defect in hypothalamic function which was a likely cause of infertility. The case is compared with previously reported examples of mitochondrial myopathy with myoclonic epilepsy, and contrasted with the Kearns-Sayre syndrome. It is concluded that mitochondrial myopathy, myoclonic epilepsy and ataxia may be distinguishing features of a specific familial disease, which on presentation may mimic the Ramsay-Hunt syndrome.

\begin{abstract}
Mitochondrial myopathy ${ }^{1-11}$ may occur with hypermetabolism or with multi-system abnormalities. When it is associated with ptosis, ophthalmoplegia, retinal pigmentation and heart block, the combination of clinical features is known as the Kearns-Sayre syndrome. ${ }^{1-4}$ We present a case of mitochondrial myopathy with lactic acidaemia and multi-system abnormalities in which (1) the presenting neurological features were ataxia and myoclonus, (2) ptosis and ophthalmoplegia, retinal pigment deposits and heart block were absent, and (3) endocrine function tests demonstrated a defect in hypothalamic function as the likely cause of infertility.
\end{abstract}

\section{Case report}

The patient, a female born in February 1949, presented in January 1975 with a four-year history of drop attacks and myoclonic jerks. Her mother and a maternal aunt suffered from involuntary movements. Another maternal aunt required a walking frame, and had a fit two months before dying with myocardial degeneration at age 27 years. This aunt's daughter died in childhood with epilepsy. On examination our patient had nystagmus, ataxia and mild dysmetria. She

Address for reprint requests: Dr $\mathbf{R}$ Fitzsimons, Department of Medicine, University of Sydney, Sydney, NSW 2006, Australia.

Accepted 18 September 1980 had myoclonic jerks affecting the arms and legs. Petit mal attacks, and one grand mal convulsion, were observed during her stay in hospital. The EEG was characterised by bilateral paroxysmal $2-3 \mathrm{~Hz}$ delta activity, and 3-4 $\mathrm{Hz}$ spike and wave activity. She was commenced on clonazepam.

In 1976 she noted limb-girdle weakness and was found to have proximal muscle weakness and weakness of neck flexion, together with cerebellar incoordination. Deep tendon reflexes and sensory examination were normal. Serum creatine phosphokinase (CPK) was $126 \mathrm{u} / 1$ (normal <50) and lactic dehydrogenase (LDH) $910 \mathrm{u} / 1 \quad(<300)$. CSF protein was $0.46 \mathrm{~g} / \mathrm{l}$. Thyroid function tests and electrocardiogram were normal. Fasting serum lactate was $4.3 \mathrm{mmol} / \mathrm{l}$ (1.0-1.78) and pyruvate $80 \mu \mathrm{mol} / 1$ (41-68). The electromyogram was myopathic, with low-amplitude polyphasic units in areas of the right deltoid, biceps and quadriceps muscles. Biopsy of the left deltoid muscle revealed multiple ragged red fibres demonstrated with the modified Gomori trichrome stain and the succinic dehydrogenase reaction. On electron microscopy there were widespread striking structural mitochondrial abnormalities, including rectangular inclusions with horizontally orientated periodicity (fig 1), paracrystalline and dense inclusions, peripheral cristae surrounding amorphous material within the mitochondria (fig 1), concentric cristae (fig 2) and bizarre enlarged forms. Abnormal lipid conglomerates within muscle fibres and cytoplasmic bodies also were seen.

She later presented for investigation because of 


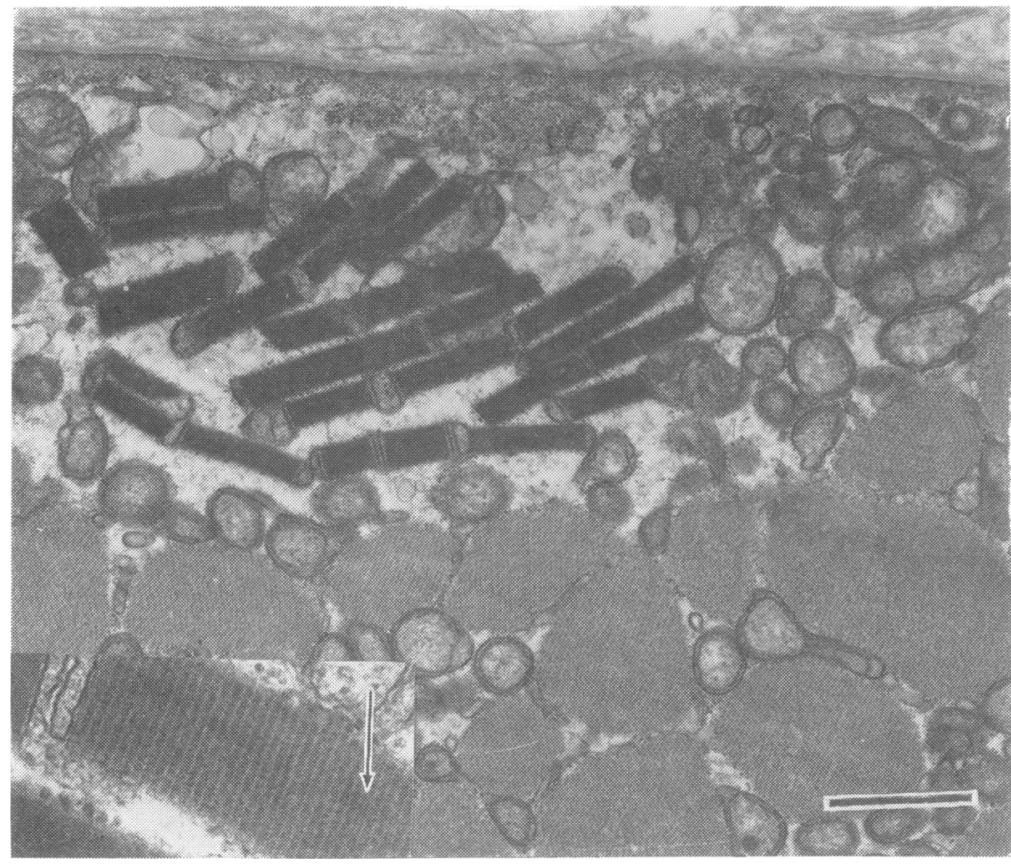

Fig 1 Abnormal mitochondria with increased matrix and rectangular inclusions. Bar $=$ 1 micron. Insert $(4 \times$ higher magnification) shows periodicity perpendicular to the long axis of the inclusions, which appear to be formed by stacking of cristae. The dark bands appear split (example arrowed), which suggests that they may consist of apposing membranes.

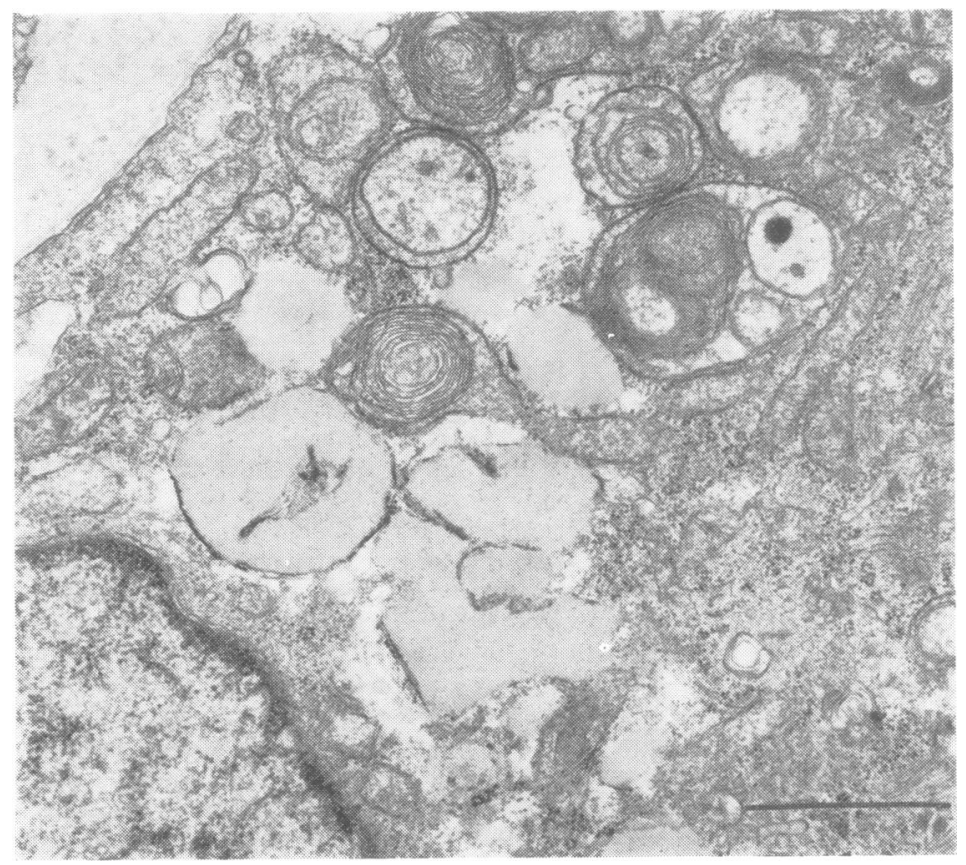

Fig 2 Mitochondria with concentric cristae and dense inclusion. There are nearby fat globules. Bar $=1$ micron.

infertility. Menarche had occurred at age 13 years, but menstruation subsequently was irregular. Her husband's semen analysis was normal. The patient's random serum oestradiol was $230 \mathrm{pmol} / 1$ (normal follicular range $75-750 \mathrm{pmol} / \mathrm{l})$. The serum luteinising hormone (LH) was $98 \mathrm{ng} / \mathrm{ml}$ (20-100 ng/ml, LER 907 standard) and the serum follicle stimulating hormone (FSH) was $110 \mathrm{ng} / \mathrm{ml}(30-200 \mathrm{ng} / \mathrm{ml}$, LER 907 
standard). The serum prolactin was $4.2 \mathrm{ng} / \mathrm{ml}$ $(<10 \mathrm{ng} / \mathrm{ml})$. Serum oestradiol levels did not rise after five days of clomiphene $50 \mathrm{mg} /$ day. Seven days later the plasma progesterone was $2.5 \mathrm{nmol} / 1$ (normal luteal phase $>15 \mathrm{nmol} / \mathrm{l})$. The addition of bromocriptine to a subsequent course of clomiphene did not enhance the oestradiol response. During a luteinising hormone releasing hormone (LHRH) infusion test (100 $\mu \mathrm{g}$ iv) the serum LH rose normally from 86 to $340 \mathrm{ng} / \mathrm{ml}$ and the serum FSH from 115 to 225 $\mathrm{ng} / \mathrm{ml}$. Following administration of exogenous FSH (75 iu/day for 3 days) the 24 hour urine oestrogens rose from $41 \mu \mathrm{M}$ to $75 \mu \mathrm{M}$ and serum oestradiol rose to $332 \mathrm{pmol} / \mathrm{l}$. The combination of the failure of serum oestradiol to rise with clomiphene, the normal LHRH response, and an ovarian response to exogenous gonadotrophins suggested that the menstrual disorder was due to hypothalamic dysfunction. She was considered for treatment with exogenous gonadotrophins but had become too weak to contemplate pregnancy.

Thyroid function tests repeated in 1978 revealed low-normal values of serum thyroxine $(66.6 \mathrm{nmol} / 1-$ normal 52.0 to $175 \mathrm{nmol} / \mathrm{l})$ and tri-iodothyronine $(1 \cdot 15 \mathrm{nmol} / 1$-normal 1.00 to $2 \cdot 75 \mathrm{nmol} / \mathrm{l})$, with an elevated serum TSH level of $16.8 \mathrm{mU} / \mathrm{L}(<5 \mathrm{mU} / \mathrm{L})$. A multi-nodular goitre was palpable. She had pale optic discs with thinning of the retinal pigment layer and was irritated by bright light glare. An electrooculogram (EOG) revealed a low Arden index and there was delayed dark adaptation. Audiology revealed bilateral high-tone hearing loss. Cerebral CT scan showed no evidence of basal ganglia calcification. Formal IQ was 101 . Height measurement was $160 \mathrm{~cm}$. The following investigations have been normal: full blood count and blood film, serum calcium and parathyroid hormone, electroretinography (ERG), immune function studies, CSF albumin/globulin ratio, chromosome analysis and skull radiographs.

\section{Discussion}

The patient suffers from a mitochondrial myopathy with multi-system abnormalities including myoclonic epilepsy, hearing loss, infertility of probable hypothalamic origin, cerebellar ataxia and primary hypothyroidism, but together these features do not fulfil the criteria for any recognised clinical syndrome. In addition the ocular findings suggest sub-clinical retinal disease. The electrophysiological findings are consistent with a previous report that the EOG is more sensitive than the ERG in assessing disorders of the retinal pigment epithelium. ${ }^{12}$ Myoclonus was a striking clinical feature. The patient particularly resembles affected members of the family with lactate acidaemia described in abstract by Tsairis et al. ${ }^{13}$ They suffered from mitochondrial myopathy, myoclonic epilepsy, ataxia and hearing loss. Ptosis and ophthalmoplegia were not men- tioned. Myopathy wth cytochrome abnormality, myoclonus and ataxia were also the cardinal clinical features in Case 1 reported by Spiro et $a l .{ }^{14}$ That patient had no ptosis, ophthalmoplegia or retinal abnormality, although his son had a similar myopathy and a seizure disorder, together with ataxia, ptosis and convergence deficiency, and chorioretinitis.

Two siblings with mitochondrial myopathy and lactic acidaemia with myoclonic epilepsy, febrile focal seizures and short stature were reported by Shapira et al. ${ }^{15}$ One patient had ptosis but neither had pigmentary retinal degeneration. The CSF protein levels were mildly elevated. The patients' mother had night blindness. Guggenheim and Stumpf ${ }^{\mathbf{1 6}}$ described a family with spinocerebellar degeneration and lactate acidaemia in which the proband suffered from cerebellar dysfunction, myoclonic epilepsy, neuropathy and optic atrophy. Although muscle biopsy was not reported, a younger sibling had necropsy evidence of cerebral pathology characteristic of Leigh's disease. Pathological changes typical of Leigh's disease, in which pyruvate metabolism is frequently disturbed, have been reported in association with mitochondrial myopathy with CNS disorder. ${ }^{17}$

Our patient also exhibits hearing loss, hypogonadism, short stature and cerebellar ataxia. These features may be associated with the Kearns-Sayre syndrome. Nevertheless the cases discussed contrast with that syndrome because (1) there is associated myoclonic epilepsy (2) they appear to be familial, whereas the Kearns-Sayre syndrome is almost always sporadic (3) ptosis and ophthalmoplegia are frequently absent and (4) the very high CSF protein levels $(>1 \mathrm{~g} / \mathrm{l})$ typical of the Kearns-Sayre syndrome are not seen. The combination of mitochondrial myopathy, myoclonic epilepsy and cerebellar ataxia may be characteristic features of an inherited illness which is aetiologically distinct from other mitochondrial syndromes, and which may, on presentation, mimic the Ramsay-Hunt syndrome. ${ }^{18}$

Primary ovarian failure has been described with mitochondrial myopathy. ${ }^{11}$ However, in the present case the endocrine disturbance was hypothalamic. This is consistent with pathological evidence of hypothalamic susceptibility in generalised mitochondrial dysfunction. ${ }^{19}$ Hypothyroidism may be associated with structural abnormalities of muscle mitochondria ${ }^{20}$ but the patient's thyroid function tests were normal at the time of biopsy.

Since this case report was submitted two similar cases of mitochondrial myopathy with dys- 
synnergia myoclonica cerebellaris, but without ophthalmoplegia, have been reported. ${ }^{21}$ This further supports the concept that these patients suffer from a nosologically distinct form of mitochondrial myopathy.

The expert technical assistance of Miss $\mathbf{J}$ Baverstock, and of Mrs $L$ van der Lubbe of the University of Sydney Electron Microscope Unit, is gratefully acknowledged.

\section{References}

1 Berenberg RA, Pellock JM, DiMauro S et al. Lumping or Splitting? "Ophthalmoplegia-Plus" or Kearns-Sayre Syndrome? Ann Neurol 1977; 1: 37-54.

2 Kearns TP, Sayre GP. Retinitis pigmentosa, external ophthalmoplegia and complete heart block. Arch Ophthalmol 1958; 60:280-9.

3 Karpati G. The Kearns-Sayre-Shy syndrome. In: Vinken PJ, Bruyn GW, eds. Handbook of Clinical Neurology. Neurological Manifestations of Systemic Disease. Amsterdam: Elsevier/North Holland Biomedical Press, 1979: vol 38, chap 10.

4 Carroll JE, Zwillich C, Weil JV, Brooke MH. Depressed ventilatory response in oculocraniosomatic neuromuscular disease. Neurology (Minneap) 1976; 26:140-6.

5 Morgan-Hughes JA, Darveniza P, Kahn SN et al. A mitochondrial myopathy characterised by a deficiency in reducible cytochrome b. Brain 1977; 100:617-40.

6 DiMauro S, Bonilla E, Lee CP et al. Luft's disease. Further biochemical and ultrastructural studies of skeletal muscle in the second case. J Neurol Sci 1976; 27:217-32.

7 Schotland DL, DiMauro S, Bonilla E, Scarpa A, Lee CP. Neuromuscular disorder associated with a defect in mitochondrial energy supply. Arch Neurol 1976; 33:475-9.

8 McLeod JG, Baker W de C, Shorey CD, Kerr CB. Mitochondrial myopathy with multisystem abnormalities and normal ocular movements. J Neurol Sci 1975; 24:39-52.

9 Markesbery WR. Lactic acidemia, mitochondrial myopathy, and basal ganglia calcification. Neurology (Minneap) 1979; 29:1057-61.

10 Hackett TN, Bray PF, Ziter FA, Nyhan WL,
Creer KM. A metabolic myopathy associated with chronic lactic acidemia, growth failure and nerve deafness. $J$ Pediatr 1973; 83:426-31.

11 Julien J, Vital C, Vallat JM, Roger P, Lunel G, Vallat M. Myopathie oculaire avec hypogonadisme primaire-Anomalies mitochondriales en ultrastructure. Rev Neurol (Paris) 1973; 128: 365-77.

12 Arden GB, Fojas MR. Electrophysiological abnormalities in pigmentary degenerations of the retina. Assessment of value and basis. Arch Ophthalmol 1962; 68:369-89.

13 Tsairis P, Engel WK, Kark P. Familial myoclonic epilepsy syndrome associated with skeletal muscle mitochondrial abnormalities. Neurology (Minneap) 1973; 23:408.

14 Spiro AJ, Moore CL, Prineas JW, Strasberg PM, Rapin I. A cytochrome-related inherited disorder of the nervous system and muscle. Arch Neurol 1970; 23:103-12.

15 Shapira Y, Cederbaum SD, Cancilla PA, Nielsen D, Lippe BM. Familial poliodystrophy, mitochondrial myopathy and lactate acidemia. Neurology (Minneap) 1975; 25:614-21.

16 Guggenheim MA, Stumpf DA. Familial metabolic disease with clinicopathological findings of both Leigh's disease and adult-type spinocerebellar degeneration. Ann Neurol 1977; 2:264-5.

17 Crosby TW, Chou SM. Ragged-red fibres in Leigh's disease. Neurology (Minneap) 1974; 24: 49-54.

18 Hunt JR. Dyssynergia cerebellaris myoclonicaprimary atrophy of the dentate system: a contribution to the pathology and symptomatology of the cerebellum. Brain 1921; 44:490-538.

19 Daroff RB, Solitare GB, Pincus JH, Glaser GH. Spongiform encephalopathy with chronic progressive external ophthalmoplegia: central ophthalmoplegia mimicking ocular myopathy. Neurology (Minneap) 1966; 16:161-9.

20 Norris FH, Panner BJ. Hypothyroid myopathy. Clinical, electrophysiological and ultrastructural observations. Arch Neurol 1966; 14:574-89.

21 Fukuhara N, Tokiguchi S, Shirakawa K, Tsubaki T. Myoclonus epilepsy associated with ragged-red fibres (mitochondrial abnormalities): Disease entity or a syndrome? Light- and ElectronMicroscopic Studies of Two Cases and Review of Literature. J Neurol Sci 1980; 47:117-33. 